\title{
Structures of some lithium-containing salts of $\mathrm{Na}^{-}$
}

\author{
James L. Dye and Rui H. Huang \\ Department of Chemistry and Center for Fundamental Materials \\ Research, Michigan State University, East Lansing, MI 48824-1322
}

\begin{abstract}
Structures of $\left(\mathrm{Li}^{+}\right)_{2}\left(\mathrm{TMTCY}_{2}\left(\mathrm{CH}_{3} \mathrm{NH}^{-}\right) \mathrm{Na}^{-}, 1, \mathrm{Li}^{+}(18 \mathrm{C} 6)\left(\mathrm{CH}_{3} \mathrm{NH}_{2}\right)_{2} \mathrm{Na}^{-}\right.$, 2 , and $\mathrm{Li}^{+}(18 \mathrm{C} 6)\left(\mathrm{CH}_{3} \mathrm{NH}_{2}\right)_{2} \mathrm{Na}^{-} \cdot(18 \mathrm{C} 6)_{3}, 3$, are reported. (TMTCY is trimethyl tricyclen and $18 \mathrm{C} 6$ is 18-crown-6). 1 and 2 show "normal" four-coordination to $\mathrm{Li}^{+}$but 3 apparently has $\mathrm{Li}^{+}$in the center of a nearly planar $18 \mathrm{C} 6$ ring with $\overline{3}$ symmetry and short $(1.733 \AA) \mathrm{Li}^{+}-\mathrm{N}$ distances to two axial methylamine molecules. An alternative model with static or dynamic disorder, but normal distances, is in poorer agreement with the $\mathrm{X}$-ray diffraction data.
\end{abstract}

\section{INTRODUCTION}

In the 18 years since the first synthesis of an alkalide (a salt of an alkali metal anion) (ref. 1), the structures of more than 30 alkalides and 4 electrides have been determined (ref. 2). Of the alkalides with known structure, 18 are natrides (salts of $\mathrm{Na}^{-}$, also called sodides). No lithides have yet been synthesized, but complexed $\mathrm{Li}^{+}$ions can provide the cations, with other alkali metals or trapped electrons serving as anions. In this paper we describe the structures of three previously unreported natrides in which complexed $\mathrm{Li}^{+}$serves as the cation.

The lithium cation has a pronounced tendency towards four-coordination with oxygen or nitrogen. The lithium amine compounds, $\mathrm{Li}\left(\mathrm{NH}_{3}\right)_{4}$ (ref. 3), $\mathrm{Li}\left(\mathrm{CH}_{3} \mathrm{NH}_{2}\right)_{4}$ (ref. 4), and $\mathrm{Li}^{+}$(ethylenediamine) ${ }_{2} \mathrm{Na}^{-}$(ref. 5), probably owe their stability to four rather strong $\mathrm{Li}^{+}-\mathrm{N}$ bonds. Indeed, the species $\mathrm{Li}^{+}\left(\mathrm{CH}_{3} \mathrm{NH}_{2}\right)_{4}$ is stable enough to permit its use as a solubilizing agent for sodium (as $\mathrm{Na}^{-}$) in a number of amine and ether solvents (ref. 6). The structures of crown ether complexes of $\mathrm{Li}^{+}$also tend to have four-coordinate interactions. Of interest here are the 18-crown-6 (IUPAC name: $1,4,7,10,13,16$-hexaoxacylooctadecane) complexes $\mathrm{Li}^{+}(18 \mathrm{C} 6) \mathrm{ClO}_{4}-\cdot 2 \mathrm{H}_{2} \mathrm{O}$ and $\mathrm{Li}^{+}(18 \mathrm{C6}) \mathrm{SCN}^{-} \cdot 2 \mathrm{H}_{2} \mathrm{O} \cdot \mathrm{Li}^{+} \mathrm{SCN}^{-}$(ref. 7), each of which contain $\mathrm{Li}^{+}$ions coordinated to two crown ether oxygens and two $\mathrm{H}_{2} \mathrm{O}$ molecules. Anionic coordination to $\mathrm{Li}^{+}$can also involve complexant molecules. The compound $\left(\mathrm{Li}^{+}\right)_{2}(18 \mathrm{C} 6) \cdot 2\left(\right.$ phenoxide ${ }^{-}$) has two $\mathrm{Li}^{+}$cations bound by one crown ether molecule (ref. 8), while $\mathrm{Li}^{+}(1,7$-diaza$12 \mathrm{C} 4$ ) forms a dimer with bridging $\mathrm{Li}^{+}$ions between deprotonated aza-crown molecules (ref. 9). In this compound each $\mathrm{Li}^{+}$is coordinated to five hetero-atoms, two crown ether oxygens, one crown ether neutral $\mathrm{NH}$ nitrogen and two negatively charged amide nitrogens. The $\mathrm{Li}^{+}-\mathrm{N}^{-}$bond lengths are $2.111 \AA$ while the $\mathrm{Li}^{+}-\mathrm{O}$ and $\mathrm{Li}^{+}-\mathrm{NH}$ bonds are somewhat longer $\left[2.258,2.327 \AA\left(\mathrm{Li}^{+}-\mathrm{O}\right)\right.$ and $\left.2.186 \AA\left(\mathrm{Li}^{+}-\mathrm{N}\right)\right]$. The lithium cation in the aza-cage molecule TMPAND $(4,10,15$-trimethyl 1,4,7,10, 15-pentaazabicyclo [5.5.5] eptadecane) also has five-coordinate $\mathrm{Li}^{+}$with $\mathrm{Li}^{+}-\mathrm{N}$ distances of $2.013,2.080,2.016$ and $2.077 \AA$ (ref. 10). This complexant has recently been used to synthesize the $\mathrm{Na}^{-}$salt (ref. 11). The bridging of two azacrown rings by $\mathrm{Li}^{+}$occurs in the compound $\mathrm{Li}^{+}(\mathrm{TMTCY})\left[\mathrm{Li}^{+}(\mathrm{DMTCY}) \cdot \mathrm{CH}_{3} \mathrm{NH}_{2}\right] \mathrm{Na}^{-}$ (ref. 12), to be considered later in this paper. The abbreviations TMTCY and DMTCY 
refer to trimethyl tricyclen (1,4,7-trimethyl-1,4,7-triazacyclononane) and dimethyl tricyclen (1,4-dimethyl-1,4,7-triazacyclononane), respectively.

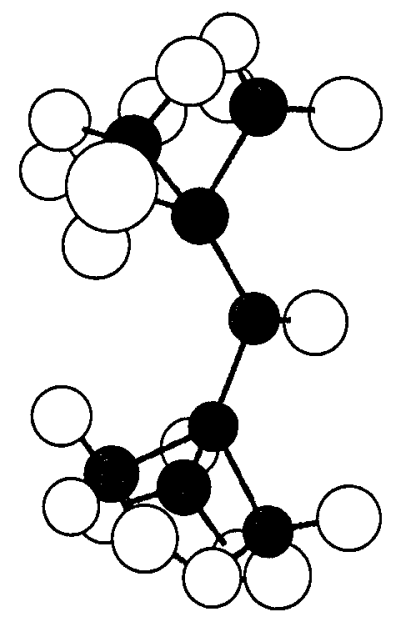

1

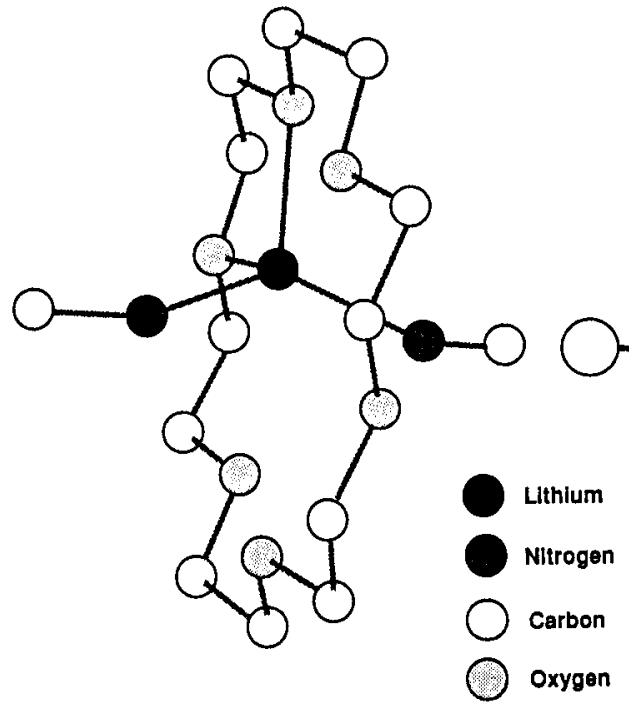

2

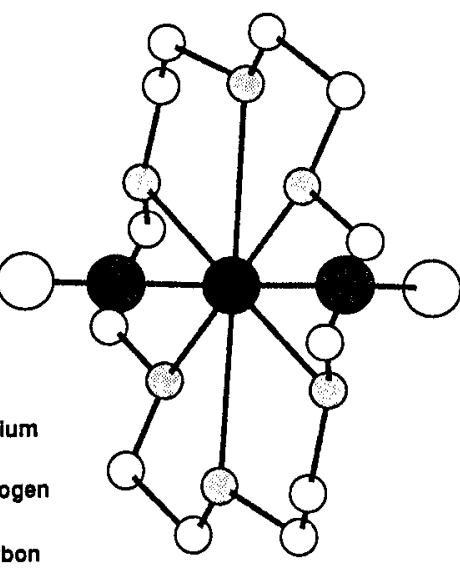

3

Fig. 1. Structures of the three lithium complexes. Not shown are the hydrogens, $\mathrm{Na}^{-}$, or the three "free" $18 \mathrm{C} 6$ molecules in 3.

\section{AZA-CROWN LITHIUM NATRIDES}

Because of the greater resistance of the aza group to irreversible reduction by $\mathrm{M}^{-}$ or $\mathrm{e}^{-}$compared with the corresponding oxo group (ref. 13), we have been exploring the use of aza-crown ethers and aza-cage complexants in the synthesis of alkalides and electrides. Tertiary amine nitrogens are required because of the tendency for $\mathrm{M}^{-}$or $\mathrm{e}^{-}$to deprotonate $\mathrm{N}-\mathrm{H}$ groups. Hexamethyl hexacyclen forms $\mathrm{Na}^{-}$salts by complexing $\mathrm{K}^{+}, \mathrm{Rb}^{+}$or $\mathrm{Cs}^{+}$(ref. 13). The corresponding pentacyclen and tetracyclen appear to have promise as $\mathrm{Li}^{+}$complexants. Space-filling models of trimethyl tricyclen (TMTCY) suggested the possible formation of sandwich complexes with $\mathrm{Li}^{+}$, but lithium was insoluble in solvents such as dimethyl ether $\left(\mathrm{Me}_{2} \mathrm{O}\right)$ even in the presence of TMTCY, suggesting that TMTCY is not a powerful complexant for $\mathrm{Li}^{+}$. Crystals were obtained by dissolving $\mathrm{Li}, \mathrm{Na}$ and TMTCY in methylamine $\left(\mathrm{MeNH}_{2}\right)$, evaporating most of the $\mathrm{MeNH}_{2}$, adding $\mathrm{Me}_{2} \mathrm{O}$, and crystallizing from a mixture of $\mathrm{Me}_{2} \mathrm{O}$ and diethyl ether. Instead of the expected sandwich compound, a compound that included deprotonated DMTCY was formed. (ref. 12). In this structure, one $\mathrm{Li}^{+}$ion forms a bridge between a TMTCY molecule and the amide nitrogen of DMTCY$^{-}$. A second lithium cation is coordinated to the three nitrogens of DMTCY ${ }^{-}$and to the nitrogen of a methylamine molecule. An isolated $\mathrm{Na}^{-}$ion balances the net +1 charge on the dimeric unit.

To avoid the deprotonation problem, TMTCY without any of the incompletely methylated DMTCY was used in a second attempt to form the sandwich compound. Instead, deprotonation of $\mathrm{MeNH}_{2}$ resulted, and the $\mathrm{MeNH}^{-}$ion formed a bridge between two $\mathrm{Li}^{+}$ions, each of which completed its coordination sheath by complexation to the three nitrogen atoms of TMTCY. Thus, compound 1 , $\left(\mathrm{Li}^{+}\right)_{2}(\mathrm{TMTCY})_{2} \cdot \mathrm{CH}_{3} \mathrm{NH}^{-} \mathrm{Na}^{-}$, formed, again yielding four-coordinate $\mathrm{Li}^{+}$with an anion $\left(\mathrm{MeNH}^{-}\right)$participating in coordination to two $\mathrm{Li}^{+}$ions. Some pertinent crystal data are given in Table 1 and $\mathrm{Li}-\mathrm{N}$ distances are given in Table 2. Details of the structure of this compound and the others described in this paper will be published elsewhere. 


\section{LITHIUM 18-CROWN-6 NATRIDES}

\section{Initial synthesis}

The first isolation of a compound in which $\mathrm{Li}^{+}$is complexed by $18 \mathrm{C} 6$ and the counter-ion is $\mathrm{Na}^{-}$was accidental. During an attempt to synthesize $\mathrm{K}^{+}(18 \mathrm{C} 6) \cdot \mathrm{Na}^{-}$, $\mathrm{MeNH}_{2}$ was used as the primary solvent and some lithium metal was added to help stabilize the solution (ref. 14). Standard synthesis procedures were used (ref. 15) followed by slow cooling to promote the growth of large crystals (ref. 16). Upon removal of the solvent the material was found to be mostly amorphous or polycrystalline, except for a few shiny, golden, blocky crystals. The X-ray diffraction pattern and structure determination showed that no potassium was present, the $\mathrm{Na}^{-}$ion was well-defined, and one $18 \mathrm{C} 6$ molecule was present with methylamine (or methylamide) molecules above and below the plane of the $18 \mathrm{C} 6$ ring. We presumed that $\mathrm{Li}^{+}$was present between two methylamine molecules but the lithium occupancy was too high (2.3) and one $\mathrm{Li}^{+}-\mathrm{N}$ bond was unreasonably short

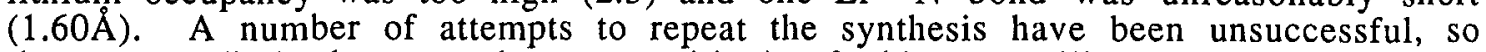
the nature (indeed, even the composition) of this crystalline natride remains a mystery.

\section{A "normal" compound, $\mathrm{Li}^{+}(18 \mathrm{C} 6) \mathrm{Na}^{-} \cdot\left(\mathrm{MeNH}_{2}\right)_{2}$}

Since we presumed that the first crystals synthesized had the composition $\mathrm{Li}^{+}(18 \mathrm{C} 6) \mathrm{Na}^{-}$and contained no potassium, subsequent syntheses were made with Li:Na:18C6 ratios of 1:1:1. These yielded a compound, 2, with the indicated stoichiometry, but the crystal structure was very different from that initially obtained. The structure of the complexed cation is similar to that of $\mathrm{Li}^{+}(18 \mathrm{C6}) \mathrm{ClO}_{4}^{-} \cdot 2 \mathrm{H}_{2} \mathrm{O}$ (ref.7). A stereoscopic view is shown in Fig 2 and some crystal data are given in Tables 1 and 2. The lithium cation is coordinated to two oxygens of $18 \mathrm{C} 6$ and to the nitrogens of two $\mathrm{MeNH}_{2}$ molecules, situated above and below the $18 \mathrm{C} 6$ ring. The $\mathrm{Li}^{+}-\mathrm{O}$ distances are 2.046 and $2.181 \AA$ and the $\mathrm{Li}^{+}-\mathrm{N}$ distances are 1.955 and $2.021 \AA$. All of these distances are normal for coordination of $\mathrm{Li}^{+}$to neutral ligands. The $\mathrm{Na}^{-}$ion is well-isolated and surrounded by a "sea" of protons from the $18 \mathrm{C} 6$ and $\mathrm{MeNH}_{2}$ molecules. Thus, compound 2 was not unusual in its coordination of $\mathrm{Li}^{+}$.
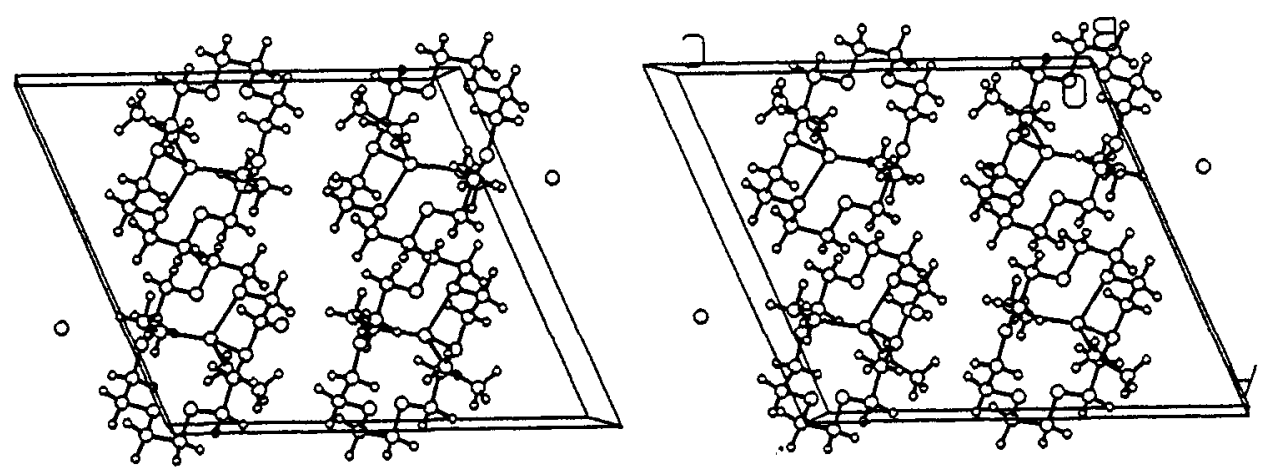

Fig. 2. Stereoscopic view of a unit cell of 2 .

\section{Structure of $\mathrm{Li}^{+}(18 \mathrm{C} 6) \mathrm{Na}^{-}\left(\mathrm{MeNH}_{2}\right)_{2} \cdot(18 \mathrm{C6})_{3}$}

Had compound 2 been obtained first, it is unlikely that attempts at further synthesis would have been made. However, the unusual nature of the first crystals prompted us to try various conditions of synthesis. When an excess of $18 \mathrm{C} 6$ was used, the unusual compound $\mathrm{Li}^{+}(18 \mathrm{C} 6) \mathrm{Na}^{-} \cdot\left(\mathrm{MeNH}_{2}\right)_{2} \cdot(18 \mathrm{C} 6)_{3}, 3$, was formed, in which three "free" crown ether molecules are symmetrically located around a central $\mathrm{Li}^{+}(18 \mathrm{C} 6)$ unit in the rather rare space group $\mathrm{R} \overline{3}$. The three "free" $18 \mathrm{C} 6$ molecules are in their regular configuration with oygens and carbons 
Table 1. Crystallographic and refinement data for the three structures

\begin{tabular}{|c|c|c|c|}
\hline Structure & $1^{*}$ & 2 & 3 \\
\hline $\begin{array}{l}\text { Space group } \\
\text { Cell params. }\end{array}$ & $\mathrm{Pbca}$ & $\mathrm{P} 2_{1} / \mathrm{c}$ & $\mathrm{R} \overline{3}$ \\
\hline a, $\AA$ & $14.9975(53)$ & $13.8772(53)$ & $11.9817(66)$ \\
\hline $\mathrm{b}, \AA$ & $17.7177(42)$ & $12.4072(40)$ & $11.9699(49)$ \\
\hline c, $\AA$ & $22.7060(72)$ & $15.7071(67)$ & 11.9685 (49) \\
\hline$\alpha, 0$ & 90 & 90 & 99.413 (33) \\
\hline$\beta, \circ$ & 90 & $113.243(27)$ & $99.359(40)$ \\
\hline$\gamma, \circ$ & 90 & 90 & $99.591 \quad(40)$ \\
\hline$\ddot{z}$ & 8 & 4 & 1 \\
\hline Cryst. dimens., mm & $.4 \times .2 \times 1.0$ & $.5 \times .4 \times .4$ & $1.1 \times .8 \times .7$ \\
\hline No. of reflctns. meas. & 4412 & 14296 & 7848 \\
\hline $\begin{array}{l}\text { No. used in refinement } \\
\text { with } \mathrm{F}_{\mathrm{o}}{ }^{2}>3 \sigma\left(\mathrm{F}_{\mathrm{o}}{ }^{2}\right)\end{array}$ & 1505 & 2564 & 2018 \\
\hline $\mathbf{R}$ & 0.047 & 0.040 & 0.048 \\
\hline $\mathrm{R}_{\mathrm{w}}$ & 0.047 & 0.045 & 0.048 \\
\hline $\begin{array}{l}\text { High peak in final diff. } \\
\text { map, e } / \AA^{3}\end{array}$ & 0.15 & 0.41 & 0.41 \\
\hline
\end{tabular}

* Also crystallizes in space group $\mathrm{P} 22_{1} 2_{1} 2_{1}$ but with the same molecular structure.

Table 2. Selected bond distances and angles

\begin{tabular}{cccc}
\hline Structure & Bond & Bond Distance & Bond Angle \\
\hline \multirow{2}{*}{1} & Li-N ( amide) & $1.90,1.93$ & \\
& Li-N (TMTCY) & $2.06-2.14$ & \\
2 & Li-N (MeNH2) & $2.021,1.955$ & N-Li-N, 123.8 \\
& Li-O (18C6) & $2.181,2.046$ and & \\
& & $2.713-3.623$ & \\
3 & Li-N (MeNH2) & 1.733 & N-Li-N, 180 \\
& Li-O (18C6) & 2.763 & \\
\hline
\end{tabular}

alternating along the oxygen plane. They are related to one another by the 3 -fold and central symmetry. The $\mathrm{Na}^{-}$ions lie on the 3-fold axis and are well-separated from other atoms as usual.

Because of the unusual apparent structure obtained by direct methods and Fourier difference analysis, we can only be certain of the average structure. In what follows, we first describe the results obtained directly from the $\mathrm{X}$-ray diffraction data and later discuss the possible effects of dynamic or static disorder. The structure was determined for two crystals from different syntheses with essentially the same results.

The central $18 \mathrm{C} 6$ molecule has $\overline{3}$ symmetry and $\mathrm{Li}^{+}$sits exactly at the center of the oxygen plane. The $\mathrm{Li}^{+}-\mathrm{O}$ distance is $2.764 \AA$, certainly much longer than the contact distance of $2.0 \AA$. The $\mathrm{N}$ and $\mathrm{C}$ atoms of $\mathrm{MeNH}_{2}$ are on the 3-fold axis with normal $\mathrm{C}-\mathrm{N}$ distances of $1.327 \AA$ but with very short $\mathrm{Li}^{+}-\mathrm{N}$ distances of $1.733 \AA$. 
The hydrogens of all four $18 \mathrm{C} 6$ molecules were refined isotropically, but the $\mathrm{H}$ atoms of $\mathrm{MeNH}_{2}$ were located by the difference map and fixed in the final refinement. The multiplicity of $\mathrm{Li}^{+}$was refined to a value of 1.58 . Some crystal data are given in Tables 1 and 2 , and a partial stereoscopic view is shown in Fig 3.
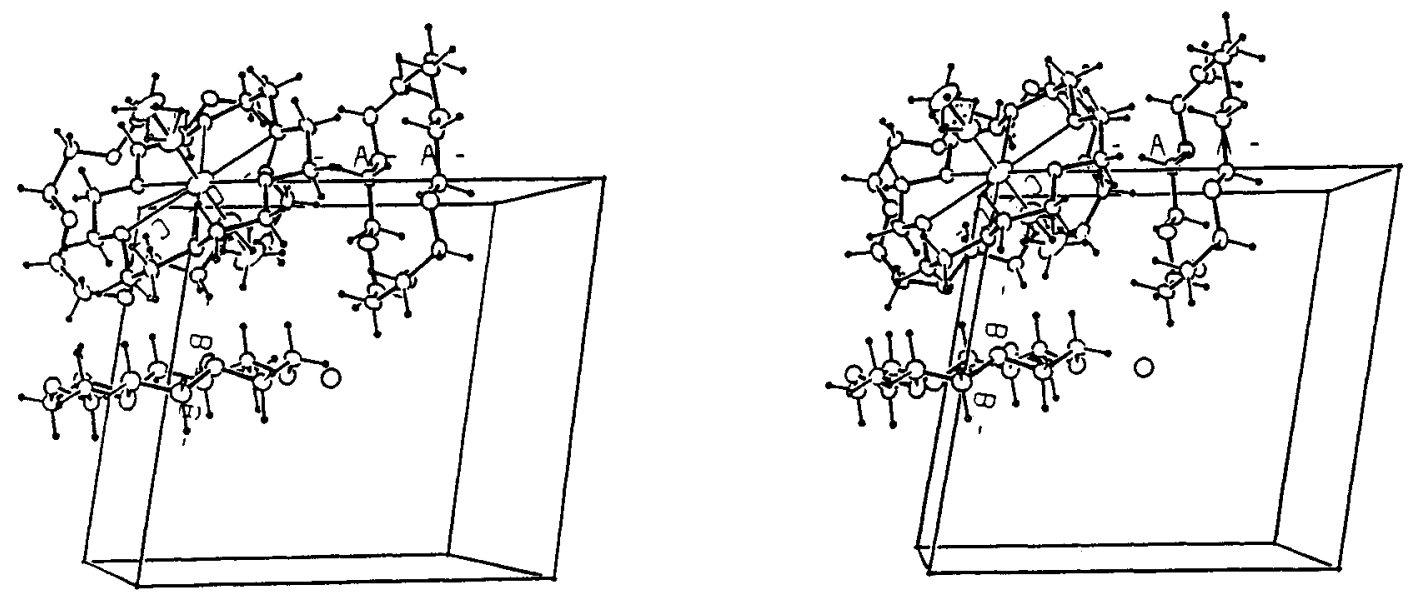

Fig. 3. Stereoscopic view of one molecule of 3 .

\section{DISCUSSION}

Two of the three structures reported here (1 and 2 ) are "normal" in the sense that $\mathrm{Li}^{+}$is four-coordinated to $\mathrm{N}$ and $\mathrm{O}$ with normal distances of $\sim 2.0 \AA$. The distance between $\mathrm{Li}^{+}$and an amide nitrogen in such structures is about $0.1 \AA$ shorter than that to an amine nitrogen. The structure of a crystal that appeared to be an isomer of 2 was very different, but our inability to repeat the synthesis leaves it as an unknown substance. It is the third structure, $\mathbf{3}$, that is unusual. We focus the remainder of the discussion on this structure.

The overall framework of the structure is not in doubt. It consists of the three "free" $18 \mathrm{C} 6$ molecules and a central one, with two $\mathrm{MeNH}_{2}$ molecules on the 3-fold axis. The thermal parameters of the $\mathrm{N}$ and $\mathrm{C}$ atoms of $\mathrm{MeNH}_{2}$ are about twice as large as anticipated for fixed molecules, but not large enough to allow significant deviations from linearity of the $\mathrm{C}-\mathrm{N} \cdots \mathrm{N}-\mathrm{C}$ chain. The major question is the location of the $\mathrm{Li}^{+}$ion and the $\mathrm{H}$ atoms of the $\mathrm{NH}_{2}$ group. If the structure is accepted at face value, it implies the existence of most unusual $\mathrm{Li}^{+}-\mathrm{N}$ bonding. According to this picture, the lithium cation forms a linear symmetric bridge between the two nitrogens with $\mathrm{Li}^{+}-\mathrm{N}$ distances of only $1.733 \AA$ to two neutral methylamine molecules. Such a structure is unprecedented, both from crystal structures and theory (refs. 17-20). Such a short distance is seen in $\mathrm{Li}^{+}$bonds to a single amide ion (ref. 17) but not to neutral molecules.

One can visualize an alternative model that preserves the average structure but has more normal bond lengths. In this model, three-fold static or dynamic disorder would be present in the $\mathrm{CH}_{3} \mathrm{H}_{2} \mathrm{~N}-\mathrm{Li}^{+}-\mathrm{NH}_{2} \mathrm{CH}_{3}$ chain by rotation about the $\mathrm{C}-\mathrm{N}$ bond. This would permit hydrogen bonding of each of the $\mathrm{NH}_{2}$ hydrogens to an ether oxygen and close interaction of $\mathrm{Li}^{+}$with two ether oxygens. The instantaneous $\mathrm{Li}^{+}-\mathrm{N}$ distance would then be about $2.0 \AA$, with a distance of $\mathrm{N}$ from the center of the ring of $\sim 1.75 \AA$. In any one configuration, all six crown ether oxygens would participate in either a hydrogen bond or in a bond to $\mathrm{Li}^{+}$, which would have a coordination number of four.

Two tests were made of this plausible model. In one, the $-\mathrm{NH}_{2}$ hydrogens were allowed to ride on the nitrogens with normal distances and angles and the $\mathrm{Li}^{+}$ion 
was left out. The hydrogen occupancies were adjusted to account for the presumed disorder. The resulting electron density difference map showed a sharp peak (1.5 $\left.\mathrm{e} / \AA^{3}\right)$ in the center of the crown ether ring. The electron density at $1.0 \AA$ from the center (where the $\mathrm{Li}^{+}$would ride according to the disorder model) was only $4 \%$ of that at the center. Thus, the residual density is not in accord with this model.

In a second test, both the $\mathrm{Li}^{+}$and the hydrogens were allowed to ride on the nitrogens, with partial occupancies included. This resulted in a marked increase in the $\mathrm{R}_{\mathrm{W}}$ factor, from 0.048 for the initial refinement to 0.079 by this model, and with an even higher peak $\left(3 \mathrm{e} / \AA^{3}\right)$ at the center of the $18 \mathrm{C} 6$ ring.

We must conclude that the disordered model used is not in accord with the X-ray diffraction data. Yet the structure with 3-fold symmetry and short $\mathrm{Li}^{+}-\mathrm{N}$ distances is so unusual (refs. 17-20) that we are reluctant to endorse it without confirmatory information. Alkalides are difficult to work with because of their reactivity and thermal instability, so that caution must be used in interpreting the data from only a few measurements. Perhaps some other disordered structure would be in better agreement with the diffraction data. Meanwhile, we are exploring other ways to characterize this compound, such as NMR, IR, neutron diffraction, etc.

\section{Acknowledgments}

This research was supported in part by U.S. National Science Foundation Solid-State Chemistry Grant No. DMR 90-17292 and by the Michigan State University Center for Fundamental Materials Research.

\section{REFERENCES}

1. a) J. L. Dye, J. M. Ceraso, M. T. Lok, B. L. Barnett and F.J. Tehan, J. Am. Chem. Soc. 96, 608 (1974). b) F. J. Tehan, B. L. Barnett and J. L. Dyc, J. Am. Chem. Soc. 96, 7203 (1974).

2. J. L. Dye in Metals in Solution, P. Damay and F. Leclerq, Eds., J. Phys. IV -Colloque C5, 1, 259 (1991).

3. J. C. Thompson, Electrons in Liquid Ammonia, Oxford University Press, Oxford, 1976.

4. A. M. Stacy, D. C. Johnson and M. J. Sienko, J. Chem. Phys. 76, 4248 (1982).

5. R. Concepcion and J. L. Dyc, J. Am. Chem. Soc. 109, 7203 (1987).

6. M. K. Faber, O. Fussa-Rydel, J. B. Skowyra, L. E. H. McMills and J. L. Dye, J. An. Chem. Soc. 111, 5957 (1989).

7. P. Groth, Acta Chem. Scand. A36, 109 (1982).

8. K. A. Watson, S. Fortier, M. P. Murchie, J. W. Bovenkamp, A. Rodrigue, G. W. Buchanan and C. I. Ratcliffe, Can.. J. Chem. 68, 1201 (1990).

9. D. Barr, D. J. Berrisford, L. Mendez, A. M. Z. Slawin, R. Snaith, J. F. Stoddart, D. J. K. Williams and D. S. Wright, Angew. Chem. Int. Ed. Engl., 30, (1991).

10. A. Bencini, A. Bianchi, A. Borselli, M. Ciampolini, E. Garcia-Espana, P. Dapporto, M. Michcloni P. Paoli, J. A. Ramirez, and B. Valtancoli, Inorg. Chem. 28, 4279 (1989).

11. J. L. Eglin, E. P. Jackson, K. J. Moeggenborg, J. L. Dye, A. Bencini and M. Micheloni, J. Inclusion Phenomena, 12, 263-274 (1992).

12. R. H. Huang, D. L. Ward and J. L. Dye, Acta Crystallogr. C46, 1835 (1990).

13. M. E. Kuchenmeister and J. L. Dye, J. Am. Chem. Soc. 111, 935 (1989).

14. D. Issa and J. L. Dye, J. Am. Chem. Soc. 104, 3781 (1982).

15. a) J. L. Dye, J. Phys. Chem. 88, 3842 (1984). b) J. L. Dye and M. G. DeBacker, Annu. Rev. Phys. Chem. 38, 271 (1987).

16. D. L. Ward, R. H. Huang and J. L. Dye, Acta Crystallogr. C44, 1374 (1988).

17. A. B. Sannigrahi, T. Kar, B. G. Niyogi, P. Hobza and P. v. R. Schleyer, Chem. Rev. 90, 1061 (1990).

18. W. Setzer and P. v. R. Schleyer, Adv. Organomet. Chem. 24, 353 (1985).

19. C. Schadc and P. v. R. Schleyer, Adv. Organonict. Chem., 27, 169 (1987).

20. U. Olsher, R. M. Izatl, J. S. Bradshaw and N. K. Dallcy, Chem. Rev. 91, 137 (1991). 